\title{
E a palavra se fez prática: direito e religião e o discurso dos direitos humanos
}

\author{
And the word was made practice: law and \\ religion and human rights discourse
}

\section{Afonso Maria das Chagas}

[a] Professor de Direito na Faculdade de Ciências Contábeis e Administração do Vale do Juruena, AJES, Juína, MT - Brasil, e-mail: afonso4@gmail.com

\section{Resumo}

O objetivo deste trabalho é traçar um paralelo entre as instituições do Direito e da Religião e suas implicações na construção discursiva dos direitos humanos. Da prédica às práticas, percebe-se que é indispensável constatar o problema das "razões fracas" que envolvem o discurso de tais direitos, bem como seu baixo potencial mobilizador quanto às condições de efetivação. Ao longo da história, tanto a Religião quanto o Direito, sobretudo na perspectiva do cristianismo, significaram um potencial mobilizador sem paralelos nas distintas e diversas configurações sociais. O discurso então instrumentalizava toda uma carga ética imprescindível no sentido de amoldar condutas ou de mobilizar insurgências, em nome de conteúdos afirmativos que levariam a práticas pessoais e coletivas de transformação da realidade. É 
necessário, portanto, problematizar essa questão a fim de sondar, em tempos atuais, o que efetivamente convence em matéria de direitos humanos, investigando o porquê de um descompasso entre o que formalmente se declara e o que concretamente se vivencia. Nesse sentido é que também se constata que a dignidade humana é, e continua sendo, uma forte razão a fundamentar os direitos humanos, porém, sua legitimação pode se tornar um perigo.

Palavras-chave: Direitos humanos. Dignidade humana. Desafios. Religião.

\section{Abstract}

The objective of this work is drawing a parallel between the institutions of law and religion and its implications for the discursive construction of human rights. The preaching practices realize that it is essential to note the problem of "weak reasons" involving the speech of such rights, as well as its low potential incentive for the conditions of effectiveness. Throughout history, both religion and the law, particularly in Christianity view, meant a potential rallying unparalleled in the distinct and diverse social settings. The speech then instrumentalized a whole load ethical imperative towards conduct or conforms to mobilize insurgencies on behalf of contents affirmative practices that would lead to personal and collective transformation of reality. Therefore necessary is to discuss this issue in order to fathom in modern times, which effectively convinces in human rights. The why of a mismatch between what is formally declared and what is experienced concretely? In this sense it is also true that human dignity is and remains a strong reason to support human rights, however, its legitimacy can become a hazard.

Keywords: Human Rights. Human Dignity. Challenges. Religion.

\section{Introdução}

A força simbólica dos direitos humanos, consagrada nas Grandes Declarações, cada vez mais vem sendo interpelada sobre o seu potencial mobilizador, a sua eficácia ou concretização. Tal reconhecimento não é dispensável, mas lhe falta um poder comunicativo e mobilizador que 
possa influenciar as relações humanas e romper a impermeável barreira do silêncio frente às sistemáticas agressões e violações de tais direitos.

A ideia de um conjunto de valores que possa fermentar as práticas pessoais, sociais e institucionais muitas vezes encontra resistência num cimentado institucionalismo, imune aos fatos e insensível aos desafios que emergem da realidade ruidosa e de tantas questões sociais que evidenciam o desrespeito e o descumprimento das propostas afirmativas dos direitos humanos. É quando o silêncio se faz instituto e o diálogo se faz monólogo. O difícil aprendizado, que diz que diante dos fatos se comete menos ambiguidades do que nas academias, nas sacristias, nos cartórios e nas academias, parece ser uma lição ainda dispensada.

Do outro lado, o pluralismo exsurge como um clamor subversivo contra os monismos dogmáticos, a (di)versidade desafia a (uni)versidade, o contexto interpela o texto, reclamando uma nova forma de comunicação. Eis, pois, o campo oportuno para que tanto a Religião quanto o Direito possam, sem culpa e sem medo, interagir com tais interpelações. Vislumbra-se, portanto, uma possibilidade (kairós) de reelaboração do discurso dos direitos humanos, na qual o racionalismo possa ser irrigado pelo diálogo, encontro e contexto.

$\mathrm{O}$ presente artigo pretende, assim, pensar nesta ponte entre o Direito e a Religião como um campo de possibilidades, onde as "razões fortes" do discurso dos direitos humanos possam ser dinamizadas, encurtando cada vez mais a distância entre o mero reconhecimento formal e a efetivação desses direitos.

\section{Um mundo em mudança: seus sentidos e sua tradução}

As profundas transformações ocorridas nas últimas décadas levaram muita gente a indagar sobre o sentido de tudo o que tem acontecido ou vem acontecendo. A busca por esse sentido e, sobretudo, a "disputa" pela produção do mesmo, fez e faz muitos se perguntarem se mudou a época ou se é, ainda, uma época de mudanças. Como viajantes de uma nau sem rumo, tantas vezes procurávamos horizontes sem que nos déssemos conta do que realmente acontecia do lado de dentro dessa 
embarcação. Vislumbraram-se sucessivas crises, justificaram-se outras quantas. Parafraseando Lewis Carroll (1980) no diálogo entre o gato e Alice no "País das Maravilhas", quedamo-nos perdidos, sendo que "para quem não sabe para onde vai, às vezes, qualquer caminho serve".

As mudanças emergidas desde o final do século XX e, sobretudo, os acontecimentos do início do século XXI ajudaram a sepultar muitas crenças, como também suscitaram muitas dúvidas. Seria, por assim dizer, o "fim da história”, como alertava Francis Fukuyama (1992) em sua obra? Poderia, neste contexto, uma terceira via emergir de algum consenso? (GIDDENS, 2005, p. 74). As respostas indicaram a emersão de um tempo não só de destruir muros antigos, mas de criar muros novos, exigidos pelo individualismo econômico, comercial e concorrencial, erigido pela paixão pelo lucro.

Os acontecimentos de setembro de 2001, enfim, ajudaram a reestruturar uma nova cartografia dos núcleos humanos frente ao medo do terrorismo e de seu projetado combate. A geografia econômica suplanta a história e subverte a sociologia, e assim pode impor concessões à paz e ao bom senso. Há lucros também na morte.

A sacramentalidade do capital o torna (oni)presente e (oni)potente ao tempo, que cobra desde logo seus sacrifícios: gera-se riqueza, mas, conditio sine qua non, aumentam-se as desigualdades, a dilapidação dos recursos naturais não renováveis e, em resumo, a destruição do planeta numa busca desenfreada por produção e exploração de commodities.

Os reflexos desta ordem transformaram cidadãos em consumidores e desigualdades em meras estatísticas. A individualização das expectativas cuidou de ressignificar um novo parâmetro para a inclusão, como uma nova ontologia cartesiana: "consumo, logo, existo". Também (onis)ciente, este novo deus conhece a todos e a tudo. A informação, portanto, despe-se de conhecimento e transveste-se de "informatização", condicionando desejos antes das necessidades - tudo a um só tempo e em todos os lugares. Subverte-se, assim, tanto o tempo como Chronos, quanto o lugar enquanto topoi. Não há mais lugares físicos comuns, não há mais contexto. Outras são as construções de sentido ou mesmo os "não lugares", como sinaliza Marc Augé (1994).

Frutos deste tempo, novos medos surgem enquanto outros ressurgem. O sentido de pertença padronizado requer a lógica do consumo como 
prerrogativa e a produção sem escalas como necessidade. Mediante tais desafios, tributos desses "tempos pós-modernos", cada vez mais configuram um "vácuo de sentido" ante as realidades humanas. É quando a economia, compulsoriamente, interpenetra a condição humana, fixando a tendência de flexibilizar tudo, inclusive os próprios direitos (CASTELLS, 2000).

Tais medos aqui se caracterizam pela descompensada falta de satisfação diante de um mundo e de uma sociedade pulverizada de coisas consumíveis. Os velhos medos ressurgidos assombram, mas não sensibilizam o suficiente. O dano à natureza, quando muito, é saneado por boas intenções dos governos e conferências do clima, nos quais muitas vezes o consenso é dispensado. Tais medos ainda são verbalizados no aumento da xenofobia, nas diversas formas de intervencionismos, entre outros.

Nesta nova realidade "mercadorizada", humanos podem ser "descartados". Assim, restaura-se a intolerância ante os "não incluídos" ou indesejados, campo fértil para os novos fascismos e para a intransigência. A insegurança, igualmente, vai se tornando cada vez mais o amuleto da humanidade, e os novos inimigos reais muitas vezes nem têm um rosto definido. Do lado de fora, os refugiados do clima, refugiados da guerra, entre outros, insistem em tornar visível a realidade tornada invisível e inaudita pelo oráculo do consumo imperativo.

Neste contexto, ainda, o "estado de exceção" vai cada vez mais se naturalizando. Para Giorgio Agamben (2004), a exceção configura-se como uma própria suspensão, em forma de condição preliminar, na qual a ordem jurídica restringe direitos, concentra poderes e administra de forma ilimitada e "justificada" a vida dos cidadãos. Esta forma de "administrar" a vida estipula-se cada vez mais não pelo viés da excepcionalidade, mas, sim, sob a ética e a ótica da "normalidade". Suspende-se a Lei em nome da defesa da lei. O Estado Democrático de Direito transmuta-se em Estado Autoritário de Direito, um "agir de exceção" cada vez tornado uma técnica de governo. Assim, a exceção toma as cores da "forma legal" (na forma da lei), na qual a regulamentação e o controle saem da excepcionalidade e convertem-se em padrão de atuação de tais Estados (AGAMBEN, 2004).

Seja em lugares comuns, como aeroportos, praças, ruas, ou seja em bairros pobres e periféricos, em territórios que representem alguma ameaça (acampamentos sem terra, territórios indígenas, morros e favelas, 
regiões que abrigam minorias étnicas, zonas de fronteiras vigiadas), o controle e a vigilância tomam a forma do Direito, da segurança jurídica, sendo possível, pois, falar em "democracia protegida" ou em "lei e ordem". Neste mesmo sentido, mas num cenário mais ampliado, Ugo Mattei e Laura Nader (2013) entendem que essa exceção tornada regra no seio do Estado de Direito configura-se como plunder, ou seja, um verdadeiro sentido de saque, pilhagem e espoliação, em nome do princípio da legalidade. Isso resulta em teses, usos e práticas neocoloniais de diversos países economicamente hegemônicos sobre países periféricos ou em desenvolvimento. Trata-se de verdadeira dilapidação dos recursos naturais, exploração desmedida de matéria prima, abuso de relações de trabalho - verdadeiros projetos imperialistas em nome da crença ou ideologia do Estado de Direito e do repaginado conceito de valores civilizacionais.

Ressurge, portanto, a ideia do "colonialismo humanitário" acompanhado da dilapidação dos recursos naturais, da redução dos direitos territoriais dos povos tradicionais, quase sempre harmonizadas pela retórica da sustentabilidade e pela governança global. Paradoxalmente, restaura-se, sob o mote do controle das migrações, a xenofobia e a intransigência, alimentadas pelo discurso da restauração étnica e do nacionalismo nas antigas nações coloniais europeias.

Conforme Ulrich Beck (2008a), instala-se uma nova "condição humana", na qual se aceita reduzir as liberdades em nome de uma ideia de segurança. Mediante as "incertezas fabricadas", por sua vez, o Estado finge ter conhecimento e controle dos riscos, tendo como base uma segurança mais ou menos "admitida" (STAGLIANÒ, 2009). Assim, essa sociedade crê na capacidade de tomar decisões sobre o euro, sobre o dólar, sobre a guerra ou sobre a paz. Beck definiu o que é viver nesta sociedade de risco ao dizer:

Vivemos numa sociedade mundial do risco, não só no sentido de que tudo se transforma em decisões cujas consequências se tornam imprevisíveis, ou no sentido das sociedades de gestão do risco, ou naquele das sociedades do discurso sobre o risco. Sociedade do risco significa, precisamente, uma constelação na qual a ideia que guia a modernidade, isto é, a ideia da controlabilidade dos efeitos colaterais e dos perigos produzidos pelas decisões tornou-se problemática, uma constelação na qual o novo saber serve para transformar os riscos imprevisíveis em riscos calculáveis, mas deste modo 
produz, por sua vez, novas imprevisibilidades, o que constringe a reflexão sobre os riscos. Através desta "reflexividade da incerteza", a indeterminabilidade do risco no presente se torna, pela primeira vez, fundamental para toda a sociedade, de modo que devemos redefinir nossa concepção da sociedade e nossos conceitos sociológicos (BECK, 2008a, s.p).

Campo propício que fertiliza esta nova "condição humana", esse novo contexto faz emergir novos fundamentalismos e intolerâncias, estipulando tanto uma nova ética quanto uma nova ótica, que se incorporam dentro do campo de disputa social. Neste compasso, Marilena Chauí compreende que, em especial nesta realidade, "a fugacidade do presente, a ausência de laços com o passado objetivo e de esperança de um futuro emancipador, suscita o reaparecimento de um imaginário de transcendência" (CHAUÍ, 2004, p. 152). É este espaço de resposta, de construção de imaginários que se torna espaço reivindicado por tantas propostas.

Mutatis mutandis, a visualização desse cenário reporta-nos a outro campo de debate, de especial maneira no âmbito dos direitos humanos. Em que se fundamenta, neste contexto, o discurso de tais direitos? Há ainda alguma validade ou eficácia prática na sua positivação? E esta positivação é por si só condição de possibilidade de concretização destes direitos?

Outra inevitável constatação é a fragilidade dos argumentos, conceitos e teorias frente à complexidade que a realidade estampa. Assim, disputa-se a compreensão do mundo. Quem atribui sentido ao que acontece em nossa volta? Se o próprio sistema jurídico ou as instituições jurídicas, os sedimentados paradigmas institucionais e as tradicionais epistemologias não conseguem dar respostas capazes e suficientes frente às fluídas e "líquidas mudanças" da modernidade (BAUMAN, 2001), como encontrar parâmetros de ressignificação? Que se diga, aliás, que muitas dessas instituições, jurídicas, políticas e até religiosas, foram concebidas mais para conservar e reagir às mudanças "não permitidas" que para interagir com o ciclo dinâmico de tais demandas.

Ainda nessa direção, opera-se um deslocamento para o espaço privado, seja das decisões jurídico-políticas, seja da dimensão técnico-racional, seja do fenômeno religioso. A privatização destas instâncias demarca a imperativa necessidade de metamorfosear também a subjetividade. Ela afigura-se, portanto, arrancada de seu contexto, sequestrada 
do seu "mundo real" e reconfigurada para um "novo mundo" proposto. Esta descontextualização frente ao mundo e a distância da realidade da vida, em amplas dimensões, contanto, abre caminho para outras formas de controle de forma inexorável. A metáfora da "salvação" dá contornos de religiosidade às pretensões substitutivas. O próprio mercado arroga para si as respostas antes dadas pela Religião. Desta forma, impinge sua própria teologia: "é preciso salvar o mercado".

A partir dessa ausência de contexto reconfiguram-se novos textos, novas linguagens. Há uma religiosidade latente nesses processos de sustentação: "novas liturgias", um novo "sentido sacrificial" e inclusive novas formas de "demonização" do que pode se opor à ordem. Relativiza-se, neste compasso, o sentido dos bens e serviços públicos e comuns e transferem-se ao espaço privado as funções de decisão e mesmo de consecução dos objetivos que a ordem impõe. Isto pode ser aplicado, sem restrições, tanto ao Direito quanto à Religião.

Quanto mais distante do "mundo da vida", melhor tal função será desenvolvida. Em nome da necessidade de "adaptar-se" aos novos tempos, impõem-se limites e fabricam-se consensos. Um desses sinais dos tempos, pois, é dar à ação jurídico-política a dimensão de um novo fundamentalismo religioso, uma nova teologia política: o fim da história como uma nova escatologia humana, um mundo sem alternativas, único paraíso possível, e a imperativa exigência de um pensamento único e de um (con)sentimento efetivo.

O fenômeno "religioso" que (re)liga e dá sentido a essa ordem mercadológica estrutura de forma discursiva e performática esta nova condição humana e seu comportamento derivado. Também a legitima por meio de uma nova linguagem que se encarrega de alimentar os consensos necessários para que nada saia do lugar. Para as razões fundamentais que estruturam os direitos humanos, estabelece-se à primeira vista como um grande obstáculo ao reconhecimento da alteridade, dos conteúdos difusos e da dimensão comunitária e inter-relacional.

A ideia de comunidade acaba desaparecendo na multidão impessoal dos fiéis. Em concreto, no nível religioso, a ideia do coletivo ou "dos comuns" (dimensão comunitária) esvai-se diante da lógica do indivíduo, 
agora reconfigurado pela ideia, pela lógica e pela retórica do sistema. Facilmente, neste âmbito, o "outro" como "diverso" é tido como adversário ou inimigo, por vezes concorrente, alguém contra quem disputo.

Assim, as categorias universais suplantam a pluralidade, a dimensão da história e do próprio tempo. O Kairós é sucedido e sufocado pelo Chronos nesse processo. Tempo medido e demarcado, afinal, time is money. Não há como não reconhecer em tais práticas uma nova dimensão ontológica, que redefine o real e o reifica pela linguagem. Narrativas e discursos corroboram a ideia e o sentido desta nova racionalidade, que, no entanto, é mítica, uma vez que dá dimensões metafísicas ou religiosas a esta concepção de mundo a partir de outras narrativas.

Nesta nova configuração, com efeito, o ícone vai substituir a convicção, o líder terá peso maior que a doutrina, e a submissão ou o assujeitamento terá um sentido maior que a adesão consciente ou de forma politizada. Ao negar a importância da contextualização, nada melhor que a lógica do fetichismo para um indispensável "enfileiramento dogmático".

Insiste-se neste aspecto pelo fato de que o discurso que fundamenta e dá razões aos direitos humanos dialoga com tais fundamentos, ou encontra neles um forte obstáculo. A negação das possibilidades de outro consenso que se firme na dignidade humana, na alteridade e na diversidade torna-se, a contrário senso, abismo instransponível para dar força de convicção ou "razões fortes" para os direitos humanos.

Um novo ethos, surgido deste contexto, apostará mais no "amoldamento" ou adestramento da consciência que na convicção da importância da dignidade humana e das suas consequências. O tele-pragmatismo, ou seja, o fenômeno religioso midiático, insiste no tempo medido, tempo tele-presencial, específico do tempo enquanto Chronos. Nesta vivência temporal e midiatizada, são redefinidas as relações possíveis dentro de um espaço formatado e limitado de participação, envolvimento e reconhecimento. Relega-se o tempo enquanto Kairós, que seria o tempo do sentido, do oportuno, tempo não medido, por ser o tempo da graça, da relação e da reciprocidade, impossíveis de enquadramento ou limitações. 
$\mathrm{Na}$ busca dos fundamentos, portanto, resta claro que a mera positivação ou formalização de conteúdos e diretrizes vinculadas aos direitos humanos precisa ser contestada. Claro também é o fato de que a Religião ou a Teologia, circunstanciadas no iter histórico com toda a sua complexidade, tornam-se instrumentos institucionais fundamentais que podem ajudar a alicerçar tais "razões fortes" de efetividade ou de inefetividade de tais direitos humanos. Enfim, a moralidade/racionalidade que dá dimensão e sentido às condutas pessoais e coletivas, emanadas seja do Direito, seja da Religião, serão sempre um caminho de possibilidades ou de interdições num mundo em mudança.

Eis, portanto, uma pertinente discussão sobre os fundamentos dos direitos humanos para além das tradições liberais, de uma leitura às vezes ingênua das grandes Declarações, do mero reconhecimento formal e positivado. Neste sentido, Fernanda Frizzo Bragato (2011, p. 13) esclarece que "os direitos humanos existem em função de um atributo humano de ordem moral que os precedem e os tornam exigíveis, a despeito de qualquer lei. Trata-se da dignidade humana, que é o princípio fundador desta espécie de direitos".

Na concepção de Carlos Santiago Nino (1989), a disposição dos direitos humanos nos direitos nacionais é somente uma consagração de tais direitos, uma recepção jurídica dos mesmos, ao que se acrescenta que, mesmo sendo os direitos humanos de índole moral e não jurídica, eles são importantes para a prática do direito, possuem um status normativo.

\section{A dignidade humana como fundamentação: uma proposta em disputa}

No contexto da fundamentação dos direitos humanos, a questão da dignidade humana emerge como uma discussão em disputa. Nas grandes Declarações de direitos do Estado liberal, o fundamento estava mais nas noções de liberdade e de igualdade que na noção de dignidade humana. Ao ser consagrado em direitos nacionais, o tema da dignidade ficara ainda deficitário, uma vez que não se aportava em uma reflexão sobre os fundamentos ético-filosóficos do que é a dignidade humana. A (ex)surgência 
de tal reconhecimento no pós-Segunda Guerra significou, para Vicente de Paulo Barretto (2010, p. 61), "a marca da humanidade diante da barbárie". Portanto, para o mesmo autor:

A dignidade se apresenta como um qualificativo do gênero humano, que torna possível identificar todos os homens como pertencentes a um mesmo gênero... Os humanos são assim considerados porque todos são dotados de uma mesma dignidade, que é critério último de reconhecimento (em cada pessoa reside, portanto, a humanidade, que se constitui no objeto de respeito a ser exigido de todos os outros homens).

Desta forma é que a dignidade humana como princípio constitui-se como fonte legitimadora dos demais direitos fundamentais. Mas, conforme Ricoeur (RICOEUR, 1978 apud BARRETO, 2010, p. 72), "a dignidade humana é semelhante a uma responsabilidade confiada”, um encargo. É por isso que repensar e ressignificar a dignidade humana, no contexto da fundamentação dos direitos humanos, significa também enfrentar o desafio de conciliar as ações do poder público (tantas vezes instrumentalizado para violações da mesma dignidade humana) e os valores implícitos e expressos no princípio da dignidade humana.

Reconhece-se, pois, que, para a modernidade a afirmação dos direitos humanos pairava sobre uma ideia ético-metafísica, abstrata, portanto, onde nem sempre a titularidade alegada destes direitos lhe garantia efetividade ou concretização. Em tal racionalidade, o reconhecimento do outro não se (des)velava. A superação e, consequentemente, a ressignificação da subjetividade nesse molde implicará novos pressupostos antropológicos. Conforme lição de Barretto e Bragato, eis aqui a importância de Kant e as bases do "imperativo categórico", do reconhecimento do outro e no outro, naquilo que o ser humano possui de igual. Por isso que a "pertença à família humana" é a conditio sine qua non para a titularidade e o gozo dos direitos humanos (BRAGATO, 2007).

Para Barretto (2010, p. 73), faz-se necessário uma permanente "adequação lógico-racional" de tal princípio em cada caso concreto, "retirando o mesmo do invólucro adjetivo em que foi envolvido pela prática jurídica". 
Até agora, resta claro que o fenômeno do reconhecimento formal, principalmente com a positivação dos direitos humanos após as grandes Declarações, traduz-se na manutenção de uma lacuna: a passagem não realizada do reconhecimento para a concretização. Mesmo a perspectiva da dignidade humana e a superação do individualismo - a concepção individualista do ser humano das teorias liberais — não supriu tal ausência. Sobre isso, Boaventura de Souza Santos alerta para o fato de que mesmo o fundamento da dignidade humana requer uma legitimidade cultural, uma vez que há concepções culturais que até se rivalizam ou são alternativas, "já que a questão dos direitos humanos transcende o direito na zona de contato". Em tal contexto, Santos propõe a ideia da "reconstrução cultural", capaz de estabelecer uma política de reconhecimento das diferenças. Para ele (SANTOS, 2002, p. 46):

A ideia de dignidade humana pode ser formulada em muitas "línguas". Em vez de serem suprimidas em nome de universalismos postulados, essas diferenças têm de se tornar mutuamente inteligíveis através de um esforço de tradução e daquilo a que chama de hermenêutica diatópica.

O discurso dos direitos humanos e de suas razões, ainda hoje advogadas, foi sedimentado no triunfo do indivíduo e de sua vontade livre e soberana, assim como na sacralização do direito de propriedade. Essa perspectiva de direitos humanos do liberalismo clássico viria a ser positivada e textualizada nas Grandes Declarações do século XVIII: da Independência das Treze Colônias e da Revolução Francesa.

Contanto, se percebe que a apropriação do conceito de direitos humanos e seu poder de efetivação não se obtêm ou se acessam pela simples positivação. Aliás, é a ineficácia desses direitos, por vezes sistematicamente violados, que questiona essa própria positivação. E é por isso também que a fundamentação dos direitos humanos, tendo como base os pressupostos do jusracionalismo e do iluminismo, parece não fornecer boas razões que legitime sua prática ou observância. Mais que base de efetivação, o discurso transmutou-se em retórica, no máximo, de referência. Muitas vezes, tal retórica ajudou justamente a violar o que devia proteger. 
Esta é a mesma linha de pensamento de Chanda Muzaffar (1999), para quem esse sentido convencional dos direitos humanos (seus vínculos com os direitos individuais, civis e políticos) é um produto do Iluminismo europeu e da secularização do pensamento. Neste sentido, o colonialismo europeu dos séculos XVI a XIX traz em seu bojo a grotesca contradição (des)autorizadora de qualquer discurso, declaração ou afirmação de direitos humanos. O extermínio de milhões de indígenas nas Américas e o tráfico e a escravização de milhões de negros na África são fenômenos-testemunhas desta constatação. Desta forma, para Muzaffar (1999, p. 26):

Enquanto a Europa ia construindo o edifício do indivíduo (direitos individuais) dentro de suas próprias fronteiras, também ia destruindo em outras bordas (terras) a pessoa humana. Por um lado, enquanto os direitos humanos iam se expandindo entre as pessoas brancas, por outro lado os Impérios europeus infligiam terríveis sofrimentos humanos sobre os habitantes de cor em outros cantos do planeta. A eliminação das populações nativas das Américas e da Australásia e a escravização de milhões de africanos durante o tráfico de escravos europeu foram duas das maiores tragédias de direitos humanos da época colonial... O Colonialismo ocidental na Ásia, Australásia, África e América Latina representa a maior e mais massiva violação sistemática dos direitos humanos que a história já viu.

A temática da dignidade humana, de igual sorte, é muito cara ao discurso religioso. Desse modo, na ordem jurídica, os traços constitutivos da dimensão teológico-cristã imprimem uma carga ética que objetiva dar resposta aos dramas humanos concretos em seus processos históricos específicos. De forma sintetizada, remete-se, pois, ao Concílio Vaticano II e mais especificamente à Constituição Gaudium et Spes (Sobre a presença da Igreja no mundo). Quanto à questão da dignidade humana, o documento conciliar reconhece que a derivação primordial de tal dignidade funda-se no fato de que "homem e mulher foram criados à imagem de Deus e redimidos por Jesus Cristo". Por isso, a "desfiguração" dessa imagem de Deus torna-se uma ofensa ao próprio Deus, o que coloca a vida e a dignidade humana como valor supremo.

O reflexo imediato dessa posição impele à necessidade de, primeiro, reconhecer essa "presença" na dignidade humana, e, em segundo lugar, 
impele à efetivação de mecanismos tanto de proteção, quanto de promoção dessa dignidade. Em outras palavras, trata-se de uma intervenção por meio de atitudes pessoais, sociais e políticas que proporcione o "bem comum" e possa contribuir de forma responsável para um desenvolvimento verdadeiramente humano e humanizante.

Neste sentido, é fundamental perceber a dimensão política desse reconhecimento. Nos termos da própria Constituição:

A consciência mais sentida da dignidade humana dá origem em diversas regiões do mundo ao desejo de instaurar uma ordem político-jurídica em que os direitos da pessoa na vida pública sejam melhor assegurados, tais como os direitos de livre reunião e associação, de expressão das próprias opiniões e de profissão privada e pública da religião. A salvaguarda dos direitos da pessoa é, com efeito, uma condição necessária para que os cidadãos, quer individualmente quer em grupo, possam participar ativamente na vida e gestão da coisa pública (CONCÍLIO VATICANO II, 2007, n. 14).

Outro caminho não se apresenta que não o da reconstituição da dignidade humana, seja para a superação de seus interditos, seja quanto ao rompimento das algemas a que muitas vezes foi submetido tal discurso teológico. Não se trata, então, só de praticar a "escuta" de tais apelos, mas de sair do invólucro a que muitas vezes foi submetido e "ir ao mundo", rumo aos seus dilemas e conflitos. A superação desse obstáculo, tantas vezes oportuno à lógica do poder temporal, reivindica uma verdadeira "travessia missionária", um "ir além", de forma (des)estabilizadora e ousada, na qual as prédicas se encontrem com as práticas, na qual se possa, sem medo e sem culpa, se deixar "contaminar pelos contextos" (FLORES, 2009), devolvendo o "anúncio da alegria e da esperança" à realidade de onde foi "sequestrado". É por essa razão que o pressuposto evangélico da missão da Igreja no mundo (Gaudium et spes) requer essa reaproximação:

As alegrias e as esperanças, as tristezas e as angústias dos homens de hoje, sobretudo dos pobres e de todos aqueles que sofrem, são também as alegrias e as esperanças, as tristezas e as angústias dos discípulos de Cristo; e não há realidade alguma verdadeiramente humana que não encontre eco no seu coração (CONCÍLIO VATICANO II, 2007, n. 1). 


\section{As aproximações entre Direito e Religião: em busca de "razões fortes" para os direitos humanos}

Tanto o discurso jurídico quanto o discurso religioso, como se percebe, podem ajudar - seja para encobrir, seja para impulsionar e alimentar - atitudes verdadeiramente emancipatórias. De igual sorte, as "razões" que potencializam uma força mobilizadora do discurso dos direitos humanos encontram no Direito e na Religião um locus institucional privilegiado.

Já foi assinalado, na verdade, que tanto a Religião quanto o Direito expressam essa dimensão performativa em relação a padrões de conduta social, de convivência e organização da vida em sociedade. Tal dimensão, igualmente, institucionaliza-se, isto é, permeia as instituições, conjuga-se com os processos sociais e políticos e, contingencialmente, se reproduz nas relações de poder ou nas relações de cooperação. Assim, nenhuma conduta humana está totalmente livre da influência de fatores externos. Mesmo admitindo a dimensão de transcendência, o ser humano é imanência. Mesmo distintas, são, portanto, dimensões de uma única realidade (BOFF, 2000).

Para Joaquín Herrera Flores (2009), em matéria de direitos humanos, de dignidade e reconhecimento, deve-se fugir dos "essencialismos" e "dogmatismos", que sempre estiveram mais à disposição de convencer os desfavorecidos da necessidade de submissão à determinada ordem dada. Para Flores, é necessário "mundanizar" o que foi colocado como "aparência”, como verdade intocável e neutra. É preciso superar a pureza conceitual pela "contaminação dos contextos" (FLORES, 2009).

Pode ocorrer, seja pelo Direito, seja pela Religião, de se implementarem tais "essencialismos" e "dogmatismos" por meio de um discurso que "sequestre" a realidade presa em um conceito, dogma, convenção ou em um Código. Se tal realidade assim se mantiver — intocável, inacessível e "protegida" - , abre-se campo para os fundamentalismos e para a alienação da subjetividade. Aproxima-se, assim, das configurações do poder pelo poder, ora estabilizando as expectativas, ora legitimando as conveniências. É quando o real se torna movediço e se opera em nome da "segurança jurídica", da "obediência hierárquica”, da ordem e da disciplina. A 
flexibilidade dá lugar à fixidez e, pelo testemunho da história, à rigidez. O autoritarismo até institui os "mestres", porém, não forma discípulos. Nessa "ausência de realidade”, portanto, há mais clientes que fiéis.

A instrumentalidade que configura a interpretação desses sistemas nos remete à dimensão histórica dessas instituições. Os sentidos religioso, cultural ou mesmo jurídico dos empreendimentos humanos nunca estiveram desligados dos fatos sociais e históricos. Nas origens, tais fenômenos ajudaram a perceber tanto a dimensão da inserção nas realidades existenciais (imanência), quanto a abertura que potencializaria o rompimento das barreiras, a superação dos interditos e a busca de novas realidades (transcendência).

François Ost (2005) recupera, de forma ilustrativa, a relação que se estabelece entre Religião e Direito na narrativa do Código da Aliança do Sinai. Mostra que ali as condições favoráveis à sua recepção foram menos essenciais que o conteúdo da lei. E isso se deu tanto por meio do resgate da memória da dor sofrida na "Casa da escravidão" (Egito), quanto no compromisso de não tolerar e nem permitir que as condições dessa realidade se repetissem. A memória histórica não só engendrou a organização de uma nova ordem social (lei negociada), como também, pela lembrança ritualizada e pelos ciclos litúrgicos, deveria ser elemento pedagógico para a sustentação desta mesma ordem (OST, 2005, p. 23).

A dimensão memorial, aliás, quase sempre se insurgiu, sobretudo nas grandes narrativas, como instrumento desestabilizador da "ordem dada”, estabelecida. Por isso que, tão emancipadora como a força questionadora dos contextos concretos, é a memória que se ativa como forma de questionamento. Ao fiat lex se precedeu o fiat lux, à "Terra prometida" se precedeu a memória da "escravidão no Egito". Entrementes, isso desvela também que, tanto quanto a memória pode emancipar o esquecimento ou a "distorção" do passado, pode também "autorizar" processos de alienação e subjugação.

De tal maneira, resta claro que é com base no diálogo e no encontro criativo e contextualizado que tanto Direito como Religião podem desvendar caminhos para a superação dos formalismos e dogmatismos que costumam desvincular as ideias e as teorias dos fatos e da realidade. 
Quanto à possibilidade dessas superações, Ost retoma a dimensão dialógica do processo do Sinai ao dizer que:

Em vez de uma afirmação autoritária da lei, é de uma aliança que se trata; em vez de uma imposição unilateral de um mandamento, o que se assiste é à negociação de uma lei dialógica. Mais ainda: por meio de uma longa e difícil aprendizagem do diálogo, não desprovido de regressões, vê-se desenrolar o relato do progressivo aperfeiçoamento de um modo interativo, dialógico, de produção da lei: um Deus e um povo aprendem juntos as condições do respeito da alteridade que passa ao mesmo tempo pela afirmação da liberdade e pelo estabelecimento da lei (OST, 2005, p. 70).

Este fato fundante, sob forma de "Grande narrativa", foi aqui evidenciado tão somente para indicar os traços vinculantes entre Religião e Direito e a carga ética com que dão sentido e resposta aos dramas humanos concretos em seus processos históricos específicos. A força emancipadora da narrativa, seja no campo religioso, seja no campo jurídico, sempre potencializará projetos de liberdade ou justificativas de opressão. Em terras latino-americanas, a força desse potencial serviu, de um lado, ao esquecimento ou (en)cobrimento, do outro, impulsionou conquistas históricas e resistências fantásticas. Conviver nessa contradição, a partir da perspectiva dos desafios, implica sempre dar um passo para além dos consensos subalternizados ou das propostas assimilacionistas ou mesmo integracionistas.

Quando se propõe hoje uma postura descolonizadora para além dos projetos transplantados e das epistemologias adotadas, busca-se justamente a superação dessa (des)memória e os seus derivados processos de invisibilização de realidades e sujeitos secularmente assujeitados pelos projetos coloniais ou neocoloniais. Neste campo, é imperativa uma releitura tanto do Direito quanto da Teologia, que, descontentes, consigam se desvincular do refúgio insólito das academias e possam ir ao encontro da história, dos fatos, da realidade. Isso tudo para que se consolide uma teoria que denuncie o cinismo dos satisfeitos e que possa encontrar ressonância no grito das massas e das ruas, que se "contamine" da realidade.

Portanto, é nas fontes e nos fundamentos do discurso histórico dos direitos humanos que encontraremos, na maioria das vezes, suas 
"razões fracas", despidas de sentido e motivação suficiente que possam mobilizar "corações e mentes" rumo a um novo consenso necessário, instrumental de efetivação de tais direitos. Isso indica que muitas vezes, ao gosto das estruturas e projetos de poder, importaram-se e transplantaram-se modelos inadequados que serviriam para justificar mais as pretensões e a lógica do próprio poder do que a lógica emancipatória e inclusiva. As variações do positivismo acadêmico e do monismo teórico, impossibilitado de ouvir e incapacitado de falar aos "ausentes" do processo histórico, mantiveram instituições e institutos adormecidos ou incapazes de acordar do sonho dogmático (Kant). Neste compasso, as "razões fracas" dos fundamentos e do discurso dos direitos humanos encontrou, por vezes, ressonância num Direito e numa Teologia impotentes frente à pluralidade e a diferença. A exigência de reconhecimento, neste sentido, foi substituída pelas pretensões da uniformidade e da universalidade. Convenciona-se, nesta lógica, pelo formalismo das Declarações ou dos cânones abstratos. O "humano fundamental" assume os contornos da positivação ou das solenes prédicas.

Tanto o sistema jurídico como o sistema religioso, portanto, carregam essa missão de dar sustento a uma concepção de mundo, de relações, de imaginários coletivos, sob a forma de uma moralidade. Por isso não bastam só os discursos, sobretudo porque o que desafia prima facie os direitos humanos é a sua negação ou a sua violação. E se a realidade, os comportamentos sociais e institucionais "desmentem" as declarações, isso é sinal evidente de que o que sustenta e mobiliza tal proposta não comporta razões suficientemente fortes que transformem ou mobilizem tais propostas em forma de vivências.

Antes de obedecer a leis ou seguir doutrinas, é preciso ter boas razões para isso. Trata-se, pois, da dimensão moral em que a alteridade, o respeito à diferença e a dignidade humana passam a ser a tradução legítima de um discurso que, enfim, justifique as práticas, o seguimento e a obediência. Eis aqui, portanto, a necessidade de um deslocamento de perspectiva - do formalismo doutrinário para o enfoque dos direitos humanos como exigência moral: o respeito ao "Outro" em sua dignidade. Só o reconhecimento legal ou as prédicas doutrinárias têm se revelado incapazes de levar a concreto o conceito e o ensinamento. Isso, é claro, 
não desqualifica a importância da "consagração" dos direitos humanos, seja na lei, seja nas pregações. Esta previsão institucional é fundamental.

Neste itinerário, quis se demonstrar em perspectiva interdisciplinar as aproximações entre o sistema do Direito e da Religião como fenômenos de trajetos próximos, com uma força tal que, de um lado, podem "naturalizar" condutas e consensos ajustados às práticas pessoais ou coletivas de desrespeito aos direitos humanos; de outro lado, podem proporcionar uma nova consciência política, traduzida em práticas de igualdade, de alteridade e respeito. Não resta dúvida, seja pelas origens, seja pelo seu potencial mobilizador, quanto à função emancipatória tanto do Direito quanto da Religião. Não por menos, fala-se hoje de uma nova semântica exigida das Doutrinas e das Instituições que ajude a compreender o sentido da vida e da realidade e expressá-lo. Do mesmo modo, menciona-se também uma nova gramática, que aponte um ajuste de significado, numa tradução contextualizada e numa nova postura dialogal destas instâncias com a sua circundante realidade, com seu tempo histórico.

\section{Conclusões}

Há um longo caminho a ser trilhado até que se passe do ensinamento e do reconhecimento formal dos direitos humanos à sua concretização. Este caminho, aliás, interpela e convoca as Instituições para outro diálogo com a modernidade. Em tempos em que tudo parece cada vez mais impessoal e mercadorizado e em que a "espiritualidade do consumo" leva a crer na impossibilidade de outro mundo possível, apenas os apelos morais e normas codificadas não dão mais conta de responder a tantos desafios.

Religião e Direito historicamente demonstraram um potencial expressivo, capaz de suscitar necessárias mudanças nas formações sociais ou então de justificar estruturas e condutas em tempos de opressão. Hoje, sobretudo, impõe-se como desafio a necessidade de superar interditos culturais que esvaziam ou "encobrem" o discurso e as razões emancipatórias dos direitos humanos. Para tanto, de início, faz-se imprescindível superar as relações de poder que distanciam tais instituições dos fatos concretos e das pessoas. 
A negação dos direitos humanos tem tido um potencial muito mais mobilizador que as proposições afirmativas. Isto parece o óbvio. Então, logo se percebe a dimensão da tarefa de (des)construir imaginários que naturalizam o desrespeito e o (des)compromisso com os direitos humanos. Mas também se coloca como urgente a tarefa de construir novos e diferentes consensos sobre valores humanos, a dignidade humana, o irredutível humano. Para essa tarefa coletiva, tanto o Direito quanto a Religião podem oferecer instrumentais indispensáveis. Neste aspecto, é fundamental uma postura testemunhal, que reproponha a "vontade do encontro" frente à "vontade do poder", o diálogo como regra e a pedagogia do exemplo como prática. Talvez por esta tarefa, então, veremos superadas tantas práticas de desrespeito, tidas como cultura e legitimadas por discursos.

\section{Referências}

AGAMBEN, G. Estado de exceção. São Paulo: Boitempo, 2004.

AUGÉ, M. Não-lugares: introdução a uma antropologia da supermodernidade. Campinas: Papirus, 1994.

BARRETTO, V. O fetiche dos direitos humanos e outros temas. Rio de Janeiro: Lumen Juris, 2010.

BAUMAN, Z. Modernidade líquida. Rio de Janeiro: J. Zahar, 2001.

BECK, U. Conditio humana: il rischio nell'età globale. Roma: Laterza, 2008a. Disponível em: <http://www.ihu.unisinos.br/noticias/noticias-anteriores/17023-uma-sociedade-mundial-do-risco >. Acesso em: 23 jul. 2013.

BECK, U. O momento cosmopolita. ComCiência, n. 104, $2008 \mathrm{~b}$.

BOFF, L. Tempo de transcendência. Rio de Janeiro: Sextante, 2000.

BRAGATO, F. F. Por uma compreensão do sentido dos direitos humanos. Controvérsia (UNISINOS), v. 2, p. 10-20, 2007. 
BRAGATO, F. F. Contribuições teóricas latino-americanas para a universalização dos direitos humanos. Revista Jurídica da Presidência, v. 13, n. 99, p. 11-31, 2011.

CARROLL, L. Aventuras de Alice no país das maravilhas: através do espelho e o que Alice encontrou lá. 3. ed. São Paulo: Summus, 1980.

CASTELLS, M. A sociedade em rede. São Paulo: Paz e Terra, 2000.

CHAUÍ, M. Fundamentalismo religioso: a questão do poder teológico-político. In: NOVAES, A. (Org.). Civilização e barbárie. São Paulo: Companhia das Letras, 2004. p. 149-169.

CONCÍLIO VATICANO II. Gaudium et spes: constituição pastoral do Concílio Vaticano II sobre a Igreja no mundo de hoje. São Paulo: Paulinas, 2007.

FLORES, J. H. A (re)invenção dos direitos humanos. Florianópolis: Fundação Boiteux, 2009.

FUKUYAMA, F. $O$ fim da história e o último homem. Rio de Janeiro: Rocco, 1992.

GIDDENS, A. A vida em uma sociedade pós-tradicional. In: BECK, U.; GIDDENS, A.; LASH, S. Modernização reflexiva: política, tradição e estética na ordem social moderna. São Paulo: Ed. UNESP, 1997. p. 73-133.

A Terceira via: reflexões sobre o impasse político atual e o futuro da social-democracia. 5. ed. Rio de Janeiro: Record, 2005.

MATTEI, U.; NADER, L. Pilhagem: quando o estado de direito é ilegal. São Paulo: M. Fontes, 2013.

MUZAFFAR, C. From human rights to human dignity. In: VAN NESS, P. (Ed.). Debating human rights: critical essays from the United States and Asia. London; New York: Routledge, 1999.

NINO, C. S. Ética y derechos humanos: un ensayo de fundamentación. Buenos Aires: Astrea, 1989. 
OST, F. Contar a lei: as fontes do imaginário jurídico. São Leopoldo: Unisinos, 2005.

RICOEUR, P. 0 conflito das interpretações. Rio de Janeiro: Imago, 1978.

SANTOS, B. de S. Para uma sociologia das ausências e uma sociologia das emergências. Revista Crítica de Ciências Sociais, n. 63, p. 237-280, 2002. Disponível em: <www.ces.uc.pt/bss/documentos/sociologia_das_ausencias. pdf $>$. Acesso em: 12 jul. 2013.

STAGLIANÒ, R. A sociedade do risco e o ano que virá. Entrevista com o sociólogo alemão Ulrich Beck, publicada originalmente em 2008, no jornal La Repubblica. São Leopoldo, Instituto Humanitas Unisinos, 2009. Disponível em: <http://www.ihu.unisinos.br/noticias/noticias-anteriores/19117-a-sociedade-do-risco-e-o-ano-que-vira>. Acesso em: 20 jul. 2013.

Recebido: 30/07/2013

Received: 07/30/2013

Aprovado: 15/04/2014

Approved: 04/15/2014 